\title{
Disaster Preparedness, Triage, and Surge Capacity for Hospital Definitive Care Areas: Optimizing Outcomes when Demands Exceed Resources
}

J. David Roccaforte, MD ${ }^{\mathrm{a}, \mathrm{b}, *}$, James G. Cushman, $\mathrm{MD}^{\mathrm{c}}$

${ }^{\mathrm{a}}$ Department of Anesthesiology, New York University, New York, NY, USA

${ }^{\mathrm{b}}$ Department of Anesthesia, Bellevue Hospital, Room 11N34, First Ave. at 27th St., New York, NY 10016, USA

${ }^{\mathrm{c}}$ Department of Surgery, University of Maryland, R. Adams Cowley Shock Trauma Center, 22 South Greene St., Baltimore, MD 21201, USA

Disaster planning must anticipate how demands imposed by a disaster reconcile with the capacity of the treating facility. Resources must be organized before an event such that they are optimally used to treat as many victims as possible, as well as to avoid overwhelming available resources. Hirshberg and colleagues [1] in 2001 defined two different scenarios based on this supply-demand relationship. By their definitions, the absolute numbers of victims are less relevant than how demands reconcile with the capacity of the receiving facility. Multiple casualty incidents (MCIs) are defined as a large number of casualties generated over a short period that are appropriately managed with existing or extended resources. Mass casualty events (MCEs) in contrast, are major medical disasters that erode organized community support mechanisms and result in casualties which overwhelm resources.

Following the September 11, 2001, attack in Lower Manhattan, several hospitals reported the volume and pattern of injuries they treated [2-4]. Consistent with existing literature describing explosive terrorist events (especially involving a building collapse), most of the victims died at the scene, there were few casualties (relative to the number killed), and even fewer critically injured patients who survived to hospitalization [5-10].

* Corresponding author. Department of Anesthesia, Bellevue Hospital, Room 11N34, First Ave. at 27th St., New York, NY 10016.

E-mail address: jdavidr@mail.com (J.D. Roccaforte). 
Analysis of all casualties reported from the three main Lower Manhattan receiving hospitals on the morning of September 11, 2001, shows that no hospital was overwhelmed by critically injured patients. Further analysis of casualty data comparing New York University-Downtown Hospital (NYU-DH) with Bellevue Hospital (BH) shows a linear association between critical mortality and overtriage, consistent with the findings of Frykberg [7].

The subsequent discussion analyzes the concept of surge capacity and reviews relevant characteristics of disaster events, victims of such events, and hospital resources. The dilemma of triage for definitive care areas (DCAs) such as operating rooms (ORs) and intensive care units (ICUs) is also presented, along with the relevant victim characteristics. Lastly, using tabletop exercises, the discussion addresses what can be done pre-event to prepare a DCA for a multiple or mass casualty event.

\section{Lower Manhattan casualty data from September 11, 2001}

On the morning of September 11, 2001, organizers of the BH surgical response recorded 169 casualties. Approximately half of the casualties were uninjured (requiring no medical evaluation beyond triage and first aid). Of patients further evaluated, only a minority required comprehensive surgical management. Table 1 includes casualty data for $\mathrm{BH}$ on September 11th and the following 6 days.

Table 2 summarizes the cumulative casualty data from the three Manhattan hospitals located below 42nd Street: two state-designated level 1 trauma centers (BH and St. Vincent's Medical Center), and one university-affiliated community hospital (NYU-DH).

A total of 1755 patients were evaluated at these three facilities during the first week. Fully $90 \%$ of patients arriving required no formal medical evaluation beyond triage and registration. For this reason, Lower Manhattan hospitals experienced what was essentially concurrent medical MCIs yielding primarily an exercise in crowd management and information processing (Fig. 1) [11].

The 181 patients evaluated over the first week at these hospitals represent an approximately threefold increase in volume. This increase in case volume

Table 1

September 11, 12-18, 2001, casualties received at Bellevue Hospital

\begin{tabular}{llllll}
\hline Time & $\begin{array}{l}\text { No. casualties } \\
\text { received }\end{array}$ & $\begin{array}{l}\text { Obviously } \\
\text { uninjured }\end{array}$ & $\begin{array}{l}\text { Patients } \\
\text { triaged }\end{array}$ & $\begin{array}{l}\text { Medical } \\
\text { evaluation }\end{array}$ & $\begin{array}{l}\text { Surgical } \\
\text { evaluation }\end{array}$ \\
\hline September 11 & 169 & 83 & 86 & 74 & 12 \\
Days 2-7 & 25 & 2 & 23 & 14 & 9 \\
Total & 194 & 85 & 109 & 88 & $\begin{array}{c}21(19 \% \text { of } 109 \\
\text { patients triaged })\end{array}$ \\
\end{tabular}

Data from Cushman JG, Pachter L, Beaton HL. Two New York City hospitals' surgical responses to the September 11, 2001, terrorist attack in New York City. J Trauma 2003;54: $147-55$. 
Table 2

September 11-18, 2001, casualties received at Lower Manhattan Hospitals

\begin{tabular}{lclllcc}
\hline Hospital & $\begin{array}{c}\text { Patients } \\
\text { received }\end{array}$ & $\begin{array}{l}\text { Obviously } \\
\text { uninjured }\end{array}$ & $\begin{array}{l}\text { Patients } \\
\text { evaluated }\end{array}$ & $\begin{array}{l}\text { Operations } \\
\text { performed }\end{array}$ & $\begin{array}{l}\text { Patient } \\
\text { transfers }\end{array}$ & Deaths \\
\hline BH & 194 & 85 & 109 & 10 & 1 & 3 \\
NYU-DH & 717 & 691 & 26 & 8 & 22 & 7 \\
$\begin{array}{l}\text { St. Vincent's } \\
\begin{array}{c}\text { Hospital } \\
\text { Total }\end{array}\end{array}$ & 844 & 798 & 46 & NA & 3 & 5 \\
& 1755 & $\begin{array}{c}1574(90 \% \text { of } \\
1755 \text { received) }\end{array}$ & $\begin{array}{c}181(10 \% \text { requiring } \\
\text { full evaluation) }\end{array}$ & $\geq 18$ & 26 & 15 \\
\hline
\end{tabular}

Abbreviation: NA, not available.

Data from Cushman JG, Pachter L, Beaton HL. Two New York City hospitals' surgical response to the September 11, 2001, terrorist attack in New York City. J Trauma 2003;54: 147-55; Feeney JM, Goldberg R, Blumenthal JA, et al. September 11, 2001, revisited. Arch Surg 2005;140:1068-73.

stressed the resources only at the hospital nearest to Ground Zero (NYUDH). To complicate matters, NYU-DH was partially disabled by simultaneous internal disasters: impaired access to the hospital, loss of electricity, and poor air quality.

\section{Triage, overtriage, critical mortality, and definitive care areas}

On October 23, 1983, a suicide truck bomb destroyed the US Marine barracks in Beirut. Lieutenant Erik Frykberg, a general surgeon, was the chief medical officer on board the USS Iwo Jima. With limited resources and staff, Dr. Frykberg managed all 112 injured survivors. The explosion generated 346 casualties, of whom 234 immediately died. Of the 112 survivors, 96 were injured. Only 19 survivors were critical, defined by an Injury Severity

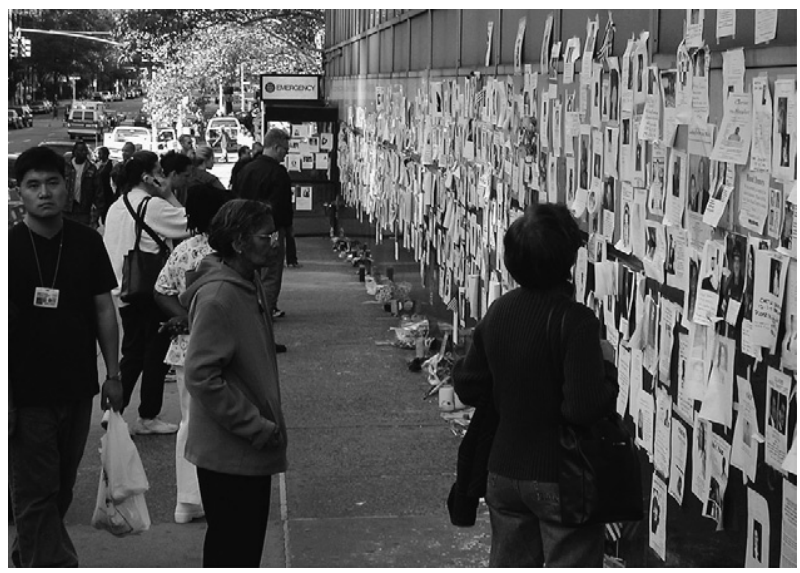

Fig. 1. Fliers posted in New York City requesting information regarding missing persons following the September 11, 2001, attacks. (Courtesy of Ken Sutin, MD, New York, NY.) 
Score (ISS) of 15 or greater. The 77 lightly injured survivors (ISS $<15$ ) created an overtriage rate $(77 / 96)$ of $80 \%$. Among the 112 initial survivors, there were 7 additional deaths, all among the 19 critically injured. Frykberg realized that the overall mortality of survivors $(7 / 112$ or $6.3 \%)$ did not tell the whole story. He concluded that a better gauge of the medical response in a disaster would be the "critical mortality," or those deaths occurring among the critically injured as a proportion of all critically injured. Because all 7 late deaths in the Beirut bombing occurred among those with an ISS greater than or equal to 15 , the critical mortality was $7 / 19$ or $37 \%$, a statistic undiluted by the majority of survivors who did not have significant injury. Of note within this definition: moribund victims with nonsurvivable injuries are not counted as initial survivors.

Frykberg reviewed multiple terrorist bombing events and noted a fascinating trend. As overtriage increases, so does critical mortality $(r=0.92)$ $[7,12]$. The explanation for this relationship is twofold. First, sorting through numerous victims to find the few critically injured takes valuable time. Second, an excess of patients who have minor injuries or no injuries prevents the DCA from functioning optimally. Predictably, radiology becomes a bottleneck; laboratory results are lost or delayed, phone lines are overloaded, medications are not properly dispensed, charts are incomplete, and staff become stressed and tired. Consequently, although individuals working in the DCAs may be under the impression that they are providing appropriate care, all of these seemingly inconsequential inadequacies conspire to increase the mortality of those patients whose lives hang in the balance and require immediate, uncompromised definitive care for survival.

Thus, while the treatment of non-critical victims is not the direct responsibility of a DCA, the consequences of their presence significantly impairs efforts to care for the critically ill and injured. Often during a disaster, caregivers adopt a siege mentality. Consequently, the insidious distractions and delays that overtriage causes are not overtly obvious to those working in the ORs and ICUs and are virtually incomprehensible to others (eg, the local officials, hospital administrators, prehospital providers, and emergency physicians who are largely responsible for planning the management of the medical response upstream from DCAs).

\section{Lower Manhattan critical mortality data from September 11, 2001}

The relationship between overtriage and critical mortality appears to have been demonstrated again on September 11, 2001. Surgeons from NYU-DH, the facility nearest to the World Trade Center, and BH analyzed and calculated their overtriage and critical mortality rates [2]. Because of its proximity, NYU-DH was flooded with psychologic casualties, the uninjured seeking refuge, people looking for missing colleagues, and critically injured victims brought in by bystanders as well as by ambulance. At BH, many ambulatory victims also arrived for evaluation, but the critically injured were 
mostly transported by emergency medical services (EMS). At BH, the overtriage rate was $80 \%$, and the critical mortality was $28 \%$, which was similar to the Beirut bombing. At NYU-DH, overtriage was $95 \%$, and the critical mortality was $44 \%$, which are the highest values reported from any disaster to date.

Placing these data points from September 11, 2001, on Frykberg's graph, the linear relationship is maintained (Fig. 2).

The challenges at NYU-DH arose from both sides of the demands/resources equation: First, mainly as a consequence of victims presenting to the nearest hospital while bypassing the EMS selection process, the resulting overtriage placed excessive demands on hospital resources. Second, because of its proximity to the tower disaster, NYU-DH's critical hospital infrastructure failed, causing an internal disaster that compromised available resources.

\section{Discussion}

\section{Surge capacity}

Dr. Tara O'Toole [13], Director of the Center for Biosecurity at the University of Pittsburgh Medical Center, emphasized three key response areas related to the state of preparation for a bioterrorist attack: (1) public health system vulnerabilities (eg, limited United States laboratory capacity for processing huge volumes of specimens), (2) inability to provide adequate doses

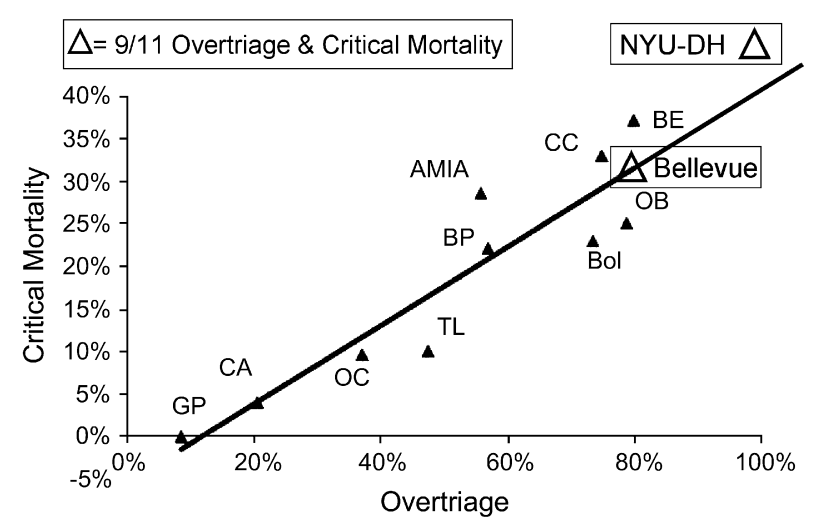

Fig. 2. Linear association between overtriage and critical mortality in selected terrorist events ( $r=0.92$ for data points). AMIA, Buenos Aires; BE, Beirut; Bol, Bologna; BP, Birmingham pubs; CA, Craigavon; CC, Cu Chi; GP, Guildford pubs; OB, Old Bailey; OC, Oklahoma City; TL, Tower of London. (Graph adapted from Frykberg ER. Medical management of disasters and mass casualties from terrorist bombings: how can we cope? J Trauma 2002;53:208; with permission. Data from Cushman JG, Pachter HL, Beaton HL. Two New York City hospitals' surgical response to the September 11, 2001, terrorist attack in New York City. J Trauma 2003;54:151.) 
of vaccinations and medications to treat major bioweapon agents, and (3) lack of hospital surge capacity or inability to expand services, primarily due to financial constraints. Subsequent to global terrorism on American soil, references to disaster preparedness surge capacity have increased [14].

For example, in US Senate testimony, Dr. Elaine Kamarck [15] stated, "recent trends in medicine in the U.S. have resulted in less capacity to deal with a 'surge' in demand for serious medical care than ever before...the absence of 'surge capacity' is serious when contemplating a high number of injuries resulting from a terrorist attack involving explosives; the absence becomes even more dangerous when contemplating the number needing medical care that could arise from a bioterrorist attack."

An early and clearly relevant use of the term "surge capacity" with regard to terrorist-related disaster threat was introduced by Smithson and Levy [16] in 2000. These authors reported that several cities "plan to establish a surge capacity at the hospitals, as well as medical outposts away from them." The idea of medical outposts referred to the creation of overflow capacity for temporarily managing excessive numbers of non-critically injured or ill victims at buildings other than the hospital, such as field centers, large indoor arenas, stadiums, schools, mobile field care centers, and so forth [16]. Rational and appropriate management of such noncritical casualties is an integral component to instituting surge capacity at any level; excessive casualties inappropriately triaged will have a powerful adverse effect on critical mortality outcomes.

The casualty data from the Lower Manhattan hospital response to September 11, 2001, is illustrative of several aspects of disaster preparedness. On that date, New York City was not prepared to respond to a sudden disaster that yielded nearly 2000 casualties where $90 \%$ of victims did not require the resources of the city's trauma centers. Chelsea Piers, converted to a medical outpost, was ill-designed for critically injured patients [7] and received few, if any, injured victims. It has been suggested that the United States' shortfall in medical preparedness for such a disaster has yet to be corrected [15,17].

Before disaster planning can take place, it is important to understand the relevant characteristics of disaster events (causes), casualties (victims), resources, and how they interrelate. Planning must acknowledge that the pinnacle of the medical response to any disaster takes place in definitive care areas. Thus, a critical component of disaster planning must be preservation of DCA capability and effectiveness.

\section{Relevant characteristics of disaster events}

A simple and relevant classification scheme for DCA preparation is to consider the disaster event location (internal or external) and the speed of onset (rapid or slow) (Fig. 3). 


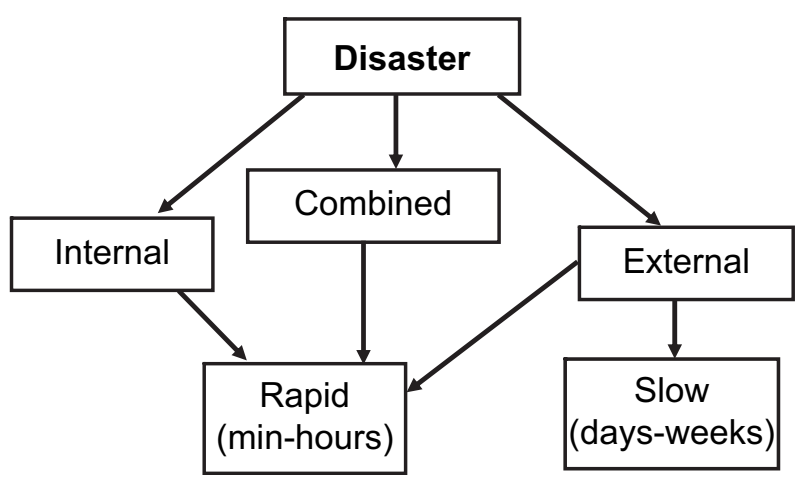

Fig. 3. Functional classification of disasters based on location and onset.

Fire [18], electrical failure [19,20], and flooding [21,22] are examples of internal disasters that affect hospital infrastructure. Examples of external disasters would include St. Vincent's Hospital and BH on September 11, 2001, or the Israeli experience in terrorist bombings $[23,24]$. Combined internal/ external disasters present particularly difficult challenges. Examples include the NYU-DH experience on September 11th, 2001, and an earthquake occurring in an urban area [25].

Slowly evolving events include infectious epidemics [26] and hurricanes [27]. With severe acute respiratory syndrome (SARS), for example, the worldwide surge in patients peaked at 56 days following initial case reports [28]. The delay in the surge of casualties allows administrators to implement plans, adjust resources, and request and obtain outside assistance. In contrast, rapidly evolving disasters require pre-event plans, frequent drills, and a self-sufficient local response that can be rapidly mobilized. Failure to have such capabilities leaves the seriously ill or injured victims most vulnerable.

Because the scope of variation in event types is so diverse, rational planning either involves generalization in broad terms (the all hazards approach), or identification of a hypothetical list of high-risk events to guide training (the hazard vulnerability analysis approach), or a combination of the two strategies [14].

\section{Relevant characteristics of victims and triage}

While unique in proportion and precedent, the September 11, 2001, attacks were illustrative of the casualty spectrum identified in most rapidly evolving disasters $[21,22]$. There were victims who were immediately killed, were not immediately killed but moribund, were critically injured with the potential for survival, others who required medical evaluation but were not critical ("walking wounded"), and those who experienced psychologic effects only ("worried well"). 
Frykberg [7] was among the first to describe the dead/injured ratio for a variety of terrorist bombings. He observed in Beirut a dead/injured ratio of 2:1, a reversal of the 1:2 to 1:5 ratio of conventional war. Frykberg further noted that the dead/injured ratio of the September 11, 2001, attack would be 5:1 or higher, and in fact, it may have approached 10:1. In most reports from various mass casualty events, deaths and injuries can be tabulated. The dead/injured ratio is proving to be a recurring statistic that correlates to the amount of physical energy released by the event.

The American College of Surgeons [29] recommends that trauma centers maintain a $50 \%$ overtriage rate for the management of casualties from physical injury under routine circumstances; ie, half of the patients triaged to a trauma center are found not to have sustained major trauma (as defined by an ISS $<15$ ). Thus, prehospital protocols are designed to encourage a degree of overtriage. The intent is to capture all serious injuries while minimizing the opposite result of undertriage and having seriously injured trauma patients inappropriately treated at nontrauma centers. Frykberg recognized that in disaster scenarios the dead may vastly outnumber the injured, and only a minority of those injured are critical $(10 \%-15 \%)$, so overtriage above and beyond the $50 \%$ mark was possible, with potentially deleterious consequences to the survival of the critically injured.

In response to multiple or mass casualty, the most basic distinction is between those casualties who are critical versus noncritical. As one follows the path of the victim from the scene, to field evacuation, to a casualty collection area, to transportation to a medical facility, through the diagnostic areas, and finally to transfer to a DCA, an ongoing process called triage takes place. The etymology derives from the French "to sort." The decisions surrounding sorting, however, are highly situational. Initial sorting of patients attempts to identify their injury or illness and route them to appropriate care. In addition, when resources are inadequate to meet needs, triage performs a second function: rationing. Rationing is the process by which scarce resources are distributed, ideally in a prioritized manner to the most needy. Rationing is a charged topic for health care in the United States, but it is a long-recognized function of triage; however, rationing is seldom employed, because resources are rarely unavailable. Rationing decisions may occur at each of multiple points between the scene and the DCA: evacuation, first aid, transport, decontamination, admission, transfer, and treatment. If resources at each step are adequate, no rationing takes place; however, in a disaster, the closer one is to the scene when evaluating resources relative to needs, the more likely that rationing must take place.

During rapidly evolving events in the field, in transit, or on arrival to the hospital, a triage officer will attach a color-coded classification tag to each victim. Black tags designate dead or moribund victims. Victims who have serious injuries requiring immediate treatment are tagged red. Yellow tags identify patients who will eventually require treatment. Green tags signify ambulatory patients who have minor injuries. In addition, most casualties 
arrive from the scene untagged and with no obvious injury; however, the untagged patients may require decontamination and counseling. All affected victims must be observed and re-evaluated, because their condition may deteriorate. Finally, several people arrive at the hospital untagged: media, family, bystanders, well-meaning volunteers, and, following a terrorist event, potentially people with nefarious intent.

The absolute and relative numbers of each type of victim triaged for any event will vary. The biggest variable in explosive urban events is the untagged mass, which depends on the number of people present, location, and time of day. Different mechanisms generate reproducible patterns of death, injury, and illness; some examples include closed-space versus open-air explosions [5] and food-borne versus airborne infectious agents. Familiarity with these patterns enables clinicians to anticipate victim type, timing, acuity, and treatment needs $[6,14]$.

The immediate focus must be on the victims with red and yellow tags. These victims' lives hang in the balance. With timely diagnosis and appropriate treatment in functional DCAs, most of these victims will live; without it, many will die [30].

\section{Relevant characteristics of resources}

DCA managers must assess medical resources based on whether they can or cannot maintain normal standard of care.

Resource categorization focuses on the ability to maintain standard of care and integrates with event characteristics and victim categorization. Resources can be categorized as normal, surge, and overflow. Normal resources define the standard of care. The authors propose a definition of surge resources as alternate equipment, locations, and personnel that can be used in the treatment of additional patients while maintaining the standard of care. In contrast, overflow resources are equipment, locations, and personnel that can be used in the treatment of additional patients, but which compromise the standard of care. As casualty loads increase, normal, surge, and overflow resources are engaged and eventually exhausted. Once all overflow resources are consumed, the system is overwhelmed. Only at this point should rationing victims' access to definitive care take place.

The surge capacity of a facility is defined simply as the total number of patients that can be managed with only normal and surge resources. Overflow capacity is likewise defined as the absolute number of patients who can be accommodated with the addition of overflow resources. In reality, as casualty loads increase during a disaster, not all resources will be exhausted while treating the same number of patients. Thus, each resource (ventilators, monitors, nursing staff, and so forth) has its own normal, surge, and overflow capacity. For planning purposes, once a single resource of the next level must be employed, the patient should be considered as being treated within 
the next level's capacity. For instance, managing a critically ill patient in the postanesthesia care unit (PACU) (a surge resource) with a 1:4 nursing care ratio (overflow strategy) would be considered as using the hospital's DCA overflow capacity.

The rationale behind distinguishing these types of resources is to clarify resource management in the face of escalating needs. From this perspective, the system can be considered to be functioning continuously along a spectrum from normal to surge to overflow to overwhelmed. Many institutions use their surge capacity on a regular basis-for example, institutions that hold patients overnight in the PACU because the ICUs are full. Once surge resources are consumed, substandard practices or resources must be used to accommodate additional patients. These overflow resources are acceptable and appropriate to treat the large numbers of noncritical victims of any disaster and may be necessary even for critical victims in extreme circumstances. However, the more surge capacity (maintaining standard of care) that can be identified beforehand and quickly mobilized for critically ill and injured victims, the greater the impact will be on overall survival from the event.

\section{Definitive care area disaster planning}

The size of an event must always be placed in the context of the medical facility's normally available resources. A small event is defined as one that results in a casualty load manageable by using the involved facility's normal resources. At the opposite end of the spectrum, an extra-large event is defined as one that overwhelms the facility by generating a casualty load that cannot be accommodated even with overflow resources. The absolute numbers of casualties accommodated at each level are higher for a large urban trauma center (Table 3) than for a freestanding rural surgical center. Neither small nor extra-large events benefit from DCA planning. Small events are routinely managed with available resources, whereas extra-large events are overwhelming by definition.

A truly overwhelming mass casualty event (MCE) mandates a triage strategy that involves rationing access to definitive care. Rationing entails difficult ethical decisions. The priority becomes saving as many victims as possible given the available resources. How to render care in these austere circumstances is not in the authors' area of expertise or within the scope of this paper; but difficult decisions must be made until outside assistance arrives. Contingency planning for an overwhelming scenario does not fall on individual departments or hospitals but rather is done regionally. Rubinson and colleagues [31] published recommendations for establishing such planning to include pre-event legislative action, public transparency, and regional, rather than single hospital, implementation.

Plans developed at the DCA manager level are designed to prevent, or at least postpone, being overwhelmed. If clinicians are overwhelmed, they will 
Table 3

Integration of disaster size with triage and rationing strategies

\begin{tabular}{|c|c|c|c|c|}
\hline & \multicolumn{4}{|l|}{ Status } \\
\hline & $\begin{array}{l}\text { Normal } \\
\text { (small event) }\end{array}$ & $\begin{array}{l}\text { MCI } \\
\text { (medium event) }\end{array}$ & $\begin{array}{l}\text { MCI } \\
\text { (large event) }\end{array}$ & $\begin{array}{l}\text { MCE (extra-large } \\
\text { event) }\end{array}$ \\
\hline Resources used & Normal & $\begin{array}{l}\text { Red and yellow: } \\
\text { surge resources } \\
\text { Green: overflow } \\
\text { resources }\end{array}$ & $\begin{array}{l}\text { Overflow } \\
\text { resources for all }\end{array}$ & $\begin{array}{l}\text { Overwhelmed } \\
\text { situation }\end{array}$ \\
\hline Rationing strategy & None & $\begin{array}{l}\text { Red and yellow: } \\
\text { no rationing } \\
\text { Green: ration } \\
\text { time-to-treat } \\
\text { (acceptable to } \\
\text { delay) }\end{array}$ & $\begin{array}{l}\text { Compromise } \\
\text { standards of } \\
\text { care }\end{array}$ & $\begin{array}{l}\text { Ration access to } \\
\text { care }\end{array}$ \\
\hline \multicolumn{5}{|c|}{ Typical numbers of victims for an urban trauma center } \\
\hline Red & 2 & 5 & 15 & Large +1 \\
\hline Yellow & 4 & 10 & 30 & Large +1 \\
\hline Green & 8 & 20 & $60+$ & Large +1 \\
\hline Untagged & $10-30$ & $30-300$ & $100-2000$ & $>2000$ \\
\hline
\end{tabular}

have to do their best with what is available until outside help arrives. If care providers are overwhelmed, they should plan on providing only basic first aid and rationing access to definitive care resources [32-35].

Regarding an overwhelming event, the treatment of critically injured victims is quickly superseded in priority by public health needs, which include provisions for food, shelter, proper sanitation facilities, and clean water [36].

The focus of DCA planning efforts is on medium and large events. Medium events are those in which the critically ill or injured can be managed while maintaining standard of care with surge capacity resources. Large events can be handled only by using auxiliary substandard overflow capacity (see Table 3).

Fire, electrical failure, and flooding are internal disaster events that affect hospital infrastructure. The medical and clinical response is to maintain patient care. For the most part, plans for internal disasters are already in place; the challenges are largely administrative and logistic. The major decision during an internal disaster is whether or not to evacuate the facility [37-40]. Plans for internal disasters and evacuation must be protocol-based, formulated in advance, activated automatically, and drilled periodically [41].

Regarding external events from the perspective of the DCA, upstream triage decisions serve to screen and select from the patients who will benefit from surgery or critical care. Rationing at this level will unfortunately deny care to precisely those patients whom the triage system has selected as most likely to benefit from DCA interventions. Provision of care without rationing is the goal of DCA disaster preparedness planning. 
Once the system identifies patients as critical and delivers them to a DCA, triage ceases to function as routing; ORs and ICUs are the best of what medicine has to offer. In a DCA, rationing is employed only as a last resort. It may be appropriate to offer less than optimal care to green tagged victims; they can be triaged to a cafeteria or gymnasium for observation and delayed treatment. The impact on the outcomes of these patients will be minimal, but when resources are compromised or withheld from those routed to DCAs, mortality will increase [30].

Special attention must be paid to patients already under treatment in DCAs [42]. The first impulse when a disaster strikes is to curtail surgery, and to discharge "stable" patients from ICUs. However, patients are in these areas before the disaster for good reasons. Published experience indicates that even in rapidly evolving disasters, there is adequate time (2-4 hours) [6] with a preordained plan for these areas to be prepared and expanded to accommodate the incoming surge of casualties.

\section{Tabletop exercises}

Tabletop exercises are planned rehearsals of MCIs or MCEs, organized to challenge the community and responders involved in the management of the disaster. The degree of sophistication of a tabletop exercise can range from simple to very complex. The simplest form is when a few individuals literally sit around a table and discuss the sequence of their responses to events of a hypothetical disaster based on a written scenario. More complex variations of exercises can be from the hospital [43] or regional level (which includes first responders, communication systems, and local agencies) $[44,45]$ to national or multinational disaster rehearsals [46,47]. Common to all of these exercises are a careful pre-event plan, some degree of reality simulation, anticipation of relevant participants' responses (often a group of observers), and most importantly, a post hoc analysis of how the response was executed. Identifying the response problems and implementing the solutions are critical components of any tabletop exercise.

Tabletop exercises for DCAs are performed by appropriate administrative and clinical leadership and represent the fundamental process by which surge and overflow capacity planning occurs. The most likely disaster scenario from a hazard vulnerability analysis [48] is considered first. The process begins by identifying all the components necessary to provide care to a typical victim. Once normal resources are identified, participants identify surge and overflow resources. At each level of care (normal, surge, overflow), the care-limiting resource is identified. Participants then explore ways to expand that specific resource. The process continues by analyzing the subsequently exposed care-limiting resources. Then the exercise is repeated, assessing the next most likely scenario, and so on. When this process is completed, the group will have generated an inventory of all normal, 
surge, and overflow resources needed to provide each level of care in the ORs and ICUs. Within each category, a sequence of resource use is defined. For instance, the sequence of locations at Bellevue Hospital (BH) where emergency surgery can be performed (with capacity in parentheses) is as follows:

surgery normally performed in ORs (15)

surge to day surgery (2), then OB (3)

overflow to cystoscopy suites (2), angio suites (2), PACU (12), and ICU

We describe the analysis of the surgical intensive care unit (SICU) capacity at $\mathrm{BH}$ to illustrate the process. $\mathrm{BH}$ recently opened a new 10-bed SICU and an 8-bed step-down unit. In 2001, during the design phase, the team decided to build the 8 step-down rooms identical to, interchangeable with, and adjacent to the 10 SICU rooms. Consequently, we can now immediately increase our ICU capacity from 10 to 18 beds by simply providing additional staffing. We consider these 18 beds our initial ICU surge capacity, achieved through the dual usage of our step-down beds. Once those 18 beds are full, the resources listed in Table 4 are necessary to provide critical care, with the additional surge capacity alternatives:

We would use anesthesia machines for ventilators. Wall oxygen would be augmented with oxygen tanks. Additional ICU beds could be located in other ICUs the PACU and ORs, and we have cooperative transfer agreements with neighboring and affiliated hospitals. Housestaff would be reassigned from ambulatory and elective rotations. Nursing administration would provide overtime, use agencies, and tap float pools to maintain staffing. With these measures, nurse staffing is our surge capacity-limiting resource. In fact, this is often our normal capacity-limiting resource. We have the physical capacity, equipment, and medical staff to care simultaneously for 96 critically ill patients with up to two thirds of these patients ventilated. Our nursing department estimates capacity to care for only a maximum of about 50 patients with a $2: 1$ ICU staffing ratio. Consequently, our surge capacity expansion efforts have endeavored to increase nurse staffing.

Table 4

ICU surge capacity

\begin{tabular}{ll}
\hline Resource & Standard of care alternatives \\
\hline Ventilators & Anesthesia machines, regional resources in $48 \mathrm{~h}$ \\
Wall $\mathrm{O}_{2}$ & $\mathrm{O}_{2}$ tanks \\
ICU beds & Other ICUs, PACU, ORs, transfers \\
House staff & Reassign \\
Nursing staff & Overtime, agency, float \\
\hline
\end{tabular}

\footnotetext{
${ }^{\mathrm{a}}$ Capacity-limiting resource.
} 
We enter the overflow capacity phase (substandard alternatives) for each of these resources as they are consumed. Table 5 describes our response for each resource.

Bag-valve-mask resuscitators would substitute for ventilators; supplemental oxygen would be abandoned for room air; and patients would be located wherever there was space. Housestaff work hour regulations would be violated and the nurse/staffing ratio exceeded. In our overflow capacity scenario, it is the number of actual beds that limits our capacity. Using these resources, we estimate being able to care for about 200 critical patients for at most 48 hours, at which time outside relief would be required. This assistance would be expected from either regional cooperative arrangements or from Strategic National Stockpile resources.

It is important to involve all clinical services and areas in these exercises to anticipate problems where surge resources overlap. An anesthesia machine in a cystoscopy suite cannot serve to expand ICU ventilator capacity at the same time that surgeons are planning on using that room to expand trauma surgical capacity.

In addition, it is imperative that all clinical support services (radiology, blood bank, laboratory services, pharmacy, dietary, sterile supply, and so forth) collaborate in these iterative tabletop exercises. During the 2003 electrical blackout at $\mathrm{BH}$, we discovered that our sterile equipment processing was not on the emergency backup generator, and $\mathrm{BH}$ no longer supports gas sterilization. Because the blackout began at 4 PM on a Thursday, most surgical instruments were either in use or dirty. Consequently, capacity to perform multiple operations was severely curtailed; fortunately, only two patients required emergency operations during the blackout.

The process of continuously identifying the capacity- or care-limiting resource is crucial. Expansion planning can then focus on that weak link. It makes no sense to devote time and energy to expanding one resource, like ORs, when their usage will be limited by lack of sterile instruments.

The advantage of defining relevant aspects of events, victims, and resources as described, and of adopting the tabletop system for developing resource expansion, is that the resulting plans can be considered to be in daily use. It is likely that several times per year, surge and even overflow resources may be needed simply due to the normal variations in admissions and

Table 5

ICU overflow capacity

\begin{tabular}{ll}
\hline Resource & Suboptimal alternatives \\
\hline Ventilators & Hand ventilate with bag-valve-mask device \\
${\text { Wall } \mathrm{O}_{2}}^{\mathrm{ICU} \text { beds }}{ }^{\mathrm{a}}$ & Room air \\
House staff & General wards, hallways \\
Nursing staff & Work hour regulation noncompliance \\
\hline
\end{tabular}

${ }^{\text {a }}$ Capacity-limiting resource. 
acuity. Incorporating disaster preparedness vernacular and algorithms into daily clinical usage maintains preparedness at a continuously high level.

A number of concepts regarding the medical DCA response to disaster have been presented. The goals are threefold. The first goal is to define an understandable vocabulary and to create a usable framework to simplify and focus planning of the tasks at hand. The second goal is to provide tools and strategies to use in developing plans for a clinical response to disaster. The final goal is to present some of the remaining challenges that seriously threaten the ability to care for patients in DCAs, and which have major consequences on overall mortality following any given event. By exposing these challenges, we hope to inspire DCA clinicians to become involved in departmental, hospital, and regional planning.

\section{Acknowledgment}

The authors wish to thank Meghan E. Sise and Erick J. Arbenz, MD, for their contributions to this manuscript.

\section{References}

[1] Hirshberg A, Holcomb JB, Mattox KL. Hospital trauma care in multiple-casualty incidents: a critical view. Ann Emerg Med 2001;37:647-52.

[2] Cushman JG, Pachter L, Beaton HL. Two New York City hospitals' surgical response to the September 11, 2001, terrorist attack in New York City. J Trauma 2003;54:147-55.

[3] Feeney JM, Goldberg R, Blumenthal JA, et al. September 11, 2001, revisited. Arch Surg 2005; 140:1068-73.

[4] Marcus SG, Shamamian P, Cushman J. Remembering September 11: reflections from Bellevue Hospital and New York University Medical Center. Surgery 2002;132(3):502-5.

[5] Kluger Y, Peleg K, Daniel-Aharonson L, et al. Israeli Trauma Group. The special injury pattern in terrorist bombings. J Am Coll Surg 2004;199:875-9.

[6] Shamir MY, Weiss YG, Willner D, et al. Multiple casualty terror events: the anesthesiologist's perspective. Anesth Analg 2004;98:1746-52.

[7] Frykberg ER. Medical management of disasters and mass casualties from terrorist bombings: how can we cope? J Trauma 2002;53:201-12.

[8] Gutierrez de Ceballos JP, Turegano Fuentes F, Perez Diaz D, et al. Casualties treated at the closest hospital in the Madrid, March 11, terrorist bombings. Crit Care Med 2005;33: S107-12.

[9] Holden PJP. Improvising in an emergency. N Engl J Med 2005;353(6):541-3.

[10] Ryan J, Montgomery H. Terrorism and the medical response. N Engl J Med 2005;353(6): $543-5$.

[11] Magee M, editor. All available boats. The evacuation of Manhattan Island on September 11, 2001. New York: Spencer Books; 2002.

[12] Frykberg ER, Tepas JJ III. Terrorist bombings: lessons learned from Belfast to Beirut. Ann Surg 1988;208:569-76.

[13] O'Toole T. Congress of the United States and U.S. Senate Government Affairs Subcommittee on International Security, Proliferation and Federal Services Hearing on FEMA's Role in Managing Bioterrorist Attacks and the Impact of Public Health Concerns on Bioterrorism Preparedness testimony. July 23, 2001. Available at: http://www.upmc-biosecurity.org/ pages/resources/hearings/otoole_02.html. Accessed April 17, 2006. 
[14] Roccaforte JD, Cushman JG. Disaster preparation and management for the intensive care unit. Curr Opin Crit Care 2002;8:607-15.

[15] Kamarck E. Testimony to the Judiciary Committee of the United States Senate. November 14, 2002. Available at: http://www.ksg.harvard.edu/news/onthehill/2002/kamarck_ 111402.htm. Accessed April 17, 2006.

[16] Smithson AE, Levy LA. Ataxia: The chemical and biological terrorism threat and the U.S. response. The Henry L. Stimson Center Report No. 35, October 2000. Available at: http:// www.stimson.org/pubs.cfm?ID=12. Accessed April 17, 2006.

[17] Barbera JA, Macintyre AG, DeAtley CA. Ambulances to nowhere: America's critical shortfall in medical preparedness for catastrophic terrorism. BCSIA Discussion Paper 2001-15, ESDP Discussion Paper ESDP-2001-07, John F. Kennedy School of Government, Harvard University, October 2001. Available at: http://www.gwu.edu/ icdrm/publications/index. html. Accessed April 17, 2006.

[18] Hogan C. Responding to a fire at a pediatric hospital. AORN J 2002;75(4):793-800.

[19] Prezant DJ, Clair J, Belyaev S, et al. Effects of the August 2003 blackout on the New York City healthcare delivery system: a lesson for disaster preparedness. Crit Care Med 2005;33(1 Suppl):S96-101.

[20] Klein KR, Rosenthal MS, Klausner HA. Blackout 2003: preparedness and lessons learned from the perspectives of four hospitals. Prehospital Disaster Med 2005;20(5): 343-9.

[21] Berggren RE, Curiel TJ. After the storm-health care infrastructure in post-Katrina New Orleans. N Engl J Med 2006;354(15):1549-52.

[22] Cocanour CS, Allen SJ, Mazabob J, et al. Lessons learned from the evacuation of an urban teaching hospital. Arch Surg 2002;137(10):1141-5.

[23] Arnold JL, Halpern P, Tsai MC, et al. Mass casualty terrorist bombings: a comparison of outcomes by bombing type. Ann Emerg Med 2004;43(2):263-73.

[24] Almogy G, Belzberg H, Mintz Y, et al. Suicide bombing attacks: update and modifications to the protocol. Ann Surg 2004;239(3):295-303.

[25] Emami MJ, Tavakoli AR, Alemzadeh H, et al. Strategies in evaluation and management of Bam earthquake victims. Prehospital Disaster Med 2005;20(5):327-30.

[26] Hawryluck L, Lapinsky SE, Stewart TE. Clinical review: SARS-lessons in disaster management. Crit Care 2005;9(4):384-9.

[27] U.S. National Weather Service. National Hurricane Center, Katrina Advisory Archive. August 23-29, 2005. Available at: http://www.nhc.noaa.gov/archive/2005/KATRINA.shtml. Accessed April 17, 2006.

[28] World Health Organization, Disease Outbreak News. Update 83-one hundred days into the outbreak, June 18, 2003. Available at: http://www.who.int/csr/don/2003_06_18/en/ index.html. Accessed April 17, 2006.

[29] Committee on Trauma. Resources for optimal care of the injured patient. Chicago: American College of Surgeons; 1993.

[30] Simchen E, Sprung CL, Galai N, et al. Survival of critically ill patients hospitalized in and out of intensive care units under paucity of intensive care unit beds. Crit Care Med 2004;32: 1654-61.

[31] Rubinson L, Nuzzo JB, Talmor DS, et al. Augmentation of hospital critical care capacity after bioterrorist attacks or epidemics: recommendations of the Working Group on Emergency Mass Critical Care. Crit Care Med 2005;33(10):2393-403.

[32] Hick JL, Hanfling D, Burstein JL, et al. Health care facility and community strategies for patient care surge capacity. Ann Emerg Med 2004;44(3):253-61.

[33] Agency for Healthcare Research and Quality. Prepared by Health Systems Research Inc. under Contract No. 290-04-0010. Altered standards of care in mass casualty events. AHRQ Publication 05-0043. Rockville (MD); 2005.

[34] Hick JL, O'Laughlin DT. Concept of operations for triage of mechanical ventilation in an epidemic. Acad Emerg Med 2006;13(2):223-9. 
[35] Koenig KL, Cone DC, Burstein JL, et al. Surging to the right standard of care. Acad Emerg Med 2006;13(2):195-8.

[36] Brodie M, Weltzien E, Altman D, et al. Experiences of Hurricane Katrina evacuees in Houston shelters: implications for future planning. Am J Public Health 2006;96(8):1402-8.

[37] Sternberg E, Lee GC, Huard D. Counting crises: US hospital evacuations, 1971-1999. Prehospital Disaster Med 2004;19(2):150-7.

[38] Schultz CH, Koenig KL, Lewis RJ. Implications of hospital evacuation after the Northridge, California earthquake. N Engl J Med 2003;348:1349-55.

[39] Berman MA, Lazar EJ. Hospital emergency preparedness-lessons learned since Northridge. N Engl J Med 2003;348:1307-8.

[40] Augustine J, Schoettmer JT. Evacuation of a rural community hospital: lessons learned from an unplanned event. Disaster Manag Response 2005;3(3):68-72.

[41] Klein JS, Weigelt JA. Disaster management, lessons learned. Surg Clin North Am 1991;71: $257-66$.

[42] Sinuff T, Kahnamoui K, Cook DJ, et al. Values ethics and rationing in critical care task force. Rationing critical care beds: a systematic review. Crit Care Med 2004;32:1588-97.

[43] Cosgrove SE, Jenckes MW, Kohri D, et al. Evaluation of hospital disaster drills: a modulebased approach. Prepared by Johns Hopkins University Evidence-Based Practice Center under Contract No. 290-02-0018. AHRQ Publication No. 04-0032. Agency for Healthcare Research and Quality. Rockville (MD); 2004.

[44] Taylor JL, Roup BJ, Blythe D, et al. Pandemic influenza preparedness in Maryland: improving readiness through a tabletop exercise. Biosecur Bioterror 2005;3(1):61-9.

[45] Jasper E, Miller M, Sweeney B, et al. Preparedness of hospitals to respond to a radiological terrorism event as assessed by a full-scale exercise. J Public Health Manag Pract 2005;(Suppl): S11-6.

[46] Smith BT, Inglesby TV, Brimmer E, et al. Navigating the storm: report and recommendations from the Atlantic Storm exercise. Biosecur Bioterror 2005;3(3):256-67.

[47] Jacobs LM, Burns KJ. Terrorism preparedness: web-based resource management and the TOPOFF 3 exercise. J Trauma 2006;60(3):566-71.

[48] Joint Commission on Accreditation of Healthcare Organizations. Special issue, emergency management in the new millenium. Jt Comm Perspect 2001;21(12):8-9. Available at: http://wwwjcrinc.com/perspectivesspecialissue. Accessed April 17, 2006. 